\title{
Luis Villoro y la transformación política a nivel ontológico
}

\section{Luis Villoro and the Transformation of Politics from an Ontological Level}

\author{
Jesús Emmanuel Ferreira González \\ IIF "Luis Villoro", Universidad Michoacana de San Nicolás de Hidalgo, México \\ vayron23@yahoo.com.mx \\ Recibido: 21/09/2016 • Aceptado: 02/02/2017
}

\begin{abstract}
Resumen
Este ensayo aborda la cuestión de si hay algún vínculo entre la moralidad social (que guarda relaciones con el poder político) y el «ser-del-devenir». Se piensa el enlace entre el «bien común» y el «Ser», es decir: se estudia el «bien común» no sólo en el seno de las relaciones intersubjetivas, sociales, sino en el «intervalo» que guardan éstas con la existencia misma. Se exponen las implicaciones ontológicas del planteamiento ético y político de Luis Villoro con miras a reflexionar sobre la siguiente pregunta: ¿puede haber una política justa orientándonos en la potencia del Ser, más bien que en el poder humano? Finalmente, se propone la tesis que afirma que la mejor vía para la transformación política es la vía ética, siempre y cuando ésta realice cambios en la política a nivel ontológico.
\end{abstract}

Palabras clave: alteridad,

descentralización, intervalo, Ser, valor.

\section{Abstract}

This essay faces the question of whether there is any link between social morality (which keeps relations with political power) and the «Being-of-becoming». It thinks of the link between «Common good» and «Being»; that is: we study «common good» not only within the social inter-relationships, but in the interval that keeps them with existence. It shows the ontological implications of the political and ethical thought of Luis Villoro in order to reflect upon the next question: Is it possible to have a just politic life, instead of power of Being than by the seek for human power? Finally, it proposes the thesis that states that the best way for a political transformation is an ethical way, as long as it makes changes to Politics in an ontological level.

Keywords: Being, decentralization, interval, otherness, value. 
Introducción

La mayor parte de las etapas de la historia de las sociedades humanas, hasta nuestros días, es una historia de luchas por el poder (de dominación de unos contra otros): ${ }^{1}$ la trama de la historia de la humanidad ha sido tejida con el hilo de la injusticia (éste ha sido la expresión característica de la potencia del poder humano), y en pocos momentos el ser humano ha orientado su comportamiento hacia el «bien común» (Villoro, 1997:73), hacia el «valor objetivo» (Villoro, 1997: 41-70), además, el bien común lo ha pensado regularmente en razón de las relaciones sociales (intersubjetivamente) y ha ignorado casi siempre su relación con la potencia del Ser; por consiguiente, ha vivido mayor tiempo en el mal (la dominación, la individualidad y la soledad), que en el bien (la libertad, la comunidad y la comunión), es decir: ha vivido durante mayor tiempo conforme al poder que lo que ha vivido conforme al valor, ${ }^{2}$ lo que implica que se ha practicado, la más de las veces, una política sin ética que una política ética, cuya razón de fondo es que casi nunca se ha pensado la relación del bien común con el Ser.

Consideraciones preliminares. La «mal-formación» de la política

Consideramos que la carencia de la vivencia del bien común y la constante expresión exuberante del poder injusto, se ha debido a que ha reinado en nuestras sociedades una «política artificial», alienante, que no deja que éste se dé o acontezca. La política alienante, que madura en la Modernidad, ha operado con un poder corrupto

1 Rememorando y parafraseando la idea que plantea Marx en el Manifiesto del Partido Comunista (1979), pero vinculándola a la problemática específica del poder.

2 Pensamos esto en el horizonte que dibujan las ideas del El poder y el valor de Luis Villoro, (1997). 
y dominante, bajo las formas gnoseológicas del ente y la representación — por ello puede llamársele política de lo óntico_-, así como con formas propias del poder; por ejemplo, la ley de lo universal en el sentido de «homogeneidad»e «identidad».

Pensamos que un modo de contrarrestar los efectos de dicha política sería una «política originaria», ${ }^{3}$ ontológica, que tiene en su modo de ser «abrir la posibilidad» de un poder honesto, justo y libertario porque está orientada, sostenemos nosotros, por las «directrices del Ser»-pero siempre y cuando lo hagamos en la perspectiva de un pensamiento de la alteridad del Ser y no de un pensamiento de la identidad entre el pensar y el Ser-.

Entendemos por «directrices del Ser» formas que no corresponden a las formas de la identidad, la representación, la objetivación, ni al pensamiento o al poder dominante; son formas del Ser que inclusive no corresponden a las construcciones del pensamiento humano; son formas que tienen su fundamento en la expresión del Ser pero en estado de alteridad, son sentidos del Ser, orientaciones de la realidad misma, escenarios vitales que va construyendo el Ser cuando expresa la potencia que tiene de suyo propio; son orientaciones del flujo de su devenir propio, sentidos del destino contingente y cambiante del Ser expresándose en la realidad existencial que, por dichas características, hemos denominado «significaciones del Ser en alteridad»; éstas, son las formas que delinean el fundamento de una

3 Una diferencia esencial entre los dos tipos de política que mencionamos va en la dirección del planteamiento de Oliver Marchart de la idea de "diferencia política" — que encontramos expuesto por Ramírez en su ensayo "El giro político del siglo XX"-, en el que, con la fórmula de la diferencia ontológica (diferencia entre el Ser y el ente), de Heidegger, plantea la diferencia entre "la política" y "lo político": "Mientras que 'política' hace referencia al orden jurídico-institucional que rige a una sociedad, esto es el 'Estado', a la estructura y funciones de lo estatal, 'político' hace referencia al campo contingente e imprevisible - necesariamente contingente e imprevisible- de las acciones y relaciones que configuran/desfiguran el mundo social-humano." (Ramírez, 2011: 83). Además, observamos en "la política" el carácter de artificial (lo contrario a lo natural), lo que está hecho por el hombre con representación y apariencia y, por ello, también la política como artificio (dispositivo para conseguir cierto fin simulando una verdad o bien común); así mismo, el elemento alienante (aquello que nos hace ser lo que no somos). Así vemos, que "la política" mantiene la forma del ente y la representación, mientras que "lo político" la del Ser y la participación en el acontecimiento del estar entre nosotros en un espacio en común. En este sentido es que apuntalaríamos nuestra postura. 
racionalidad ontológica y una perspectiva ontológica de la dimensión ética y política.

Bajo dicha perspectiva ontológica, y entendiendo por ontología el estudio del ser en cuanto que ser (Aristóteles, 2007: 67), la política tendría un fundamento ético, pero el fundamento de dicha ética sería ontológico. Desde esta perspectiva la ética estudiaría la «dimensión del valor» que se articula entre el Ser y la pluralidad de seres humanos ${ }^{4}$ en la coordenada de la vitalidad del mundo vivido o mundo de la vida (Lebenswelt), donde fluyen y se comunican las corrientes de vivencias de los seres humanos y los seres existentes del mundo, siendo éste su puente y su intervalo de enlace, coordenada en la que también se articulan las relaciones humanas y su moralidad. Mientras que la política, estudiaría el ámbito propio de las relaciones humanas en el que se articulan los vínculos originarios de nuestra sociabilidad, en los que se vive la experiencia del valor de manera comunitaria. Y pensamos que en esto consistiría el sentido de una «política ontológica de la alteridad».

La política ontológica se orienta, a diferencia de la política artificial, por la dinámica contingente del Ser y de la contingencia del devenir humano (ámbito de libertad y de poder de creación de lo valioso para una vida buena en común), y aunque no cierra la posibilidad del mal, tiene en su modo de ser el valor de abrir la posibilidad del bien, radicalmente, desde los lazos de la potencia del «Ser» y en sinergia con las acciones de los seres humanos; piensa el bien común en el espacio y tiempo que se articula entre las relaciones humanas y el devenir del Ser, dimensión ontológica y del valor.

En este escenario, reflexionamos: si la política de lo óntico, orientada por el «poder humano», ha sido injusta, ¿será que mediante una orientación ontológica de las directrices que expresa la potencia del Ser en la alteridad (un poder sobre-humano) ${ }^{5}$ podemos

4 Desde una mirada desde luego humana aunque no antropocéntrica, puesto que pretende desbordarse hasta la afirmación del valor para todo ser viviente.

5 Ramírez argumenta que el humanismo que requiere nuestra época es un sobrehumanismo. (Ramírez, 2011: 30-31) Nosotros pensamos el poder político humano en ese sentido. 
construir una política justa? ¿Se puede hacer justicia pensando el bien común en sentido ontológico?

Pensamos que el mal en la política se ha presentado en todas las épocas, pero en la Modernidad se hace evidente y, a la vez, se transparenta, mostrándose con mayor claridad el ser del poder, gracias a la racionalidad instrumental; ${ }^{6}$ asimismo, consideramos que en la Posmodernidad se metamorfosea de manera extravagante debido al desencanto de la racionalidad universal y a la caída en el relativismo, el irracionalismo y el nihilismo (Villoro, 2007: 205-222). En ambas épocas, que heredan sus efectos a la nuestra, por no decir de las demás, han reinado políticas erróneas (políticas de lo óntico), faltas de ética, que operan con «formas» ${ }^{7}$ propias del poder: en la Modernidad se practicó una política bajo la forma de la «homogeneidad» ${ }^{8}$ y de la «identidad», ${ }^{9}$ mientras que en la Posmodernidad se opta por una política de la «fragmentariedad» ${ }^{10}$ y de la «diferencia». ${ }^{11}$

Ante dicha mal-formación de la política, vemos que es deseable crear una política orientada no sólo por las «formas del valor

6 Maquiavelo distingue el tipo de racionalidad que se usa en la política: "racionalidad instrumental" que usa un lenguaje explicativo. (Villoro, "Maquiavelo: Los dos lenguajes de la política", en 1997: 95-110).

7 La forma es la figura o la constelación de significaciones que definen el ser de algo. Elaboramos esta definición a partir de la idea de "figura del mundo" de Villoro. (Villoro, "Octavio Paz: Sor Juana y su 'figura del mundo',' en 1995: 136-145.) Aunque tenemos en el horizonte del recuerdo las ideas de Aristóteles al respecto: forma es lo que le da modo de ser a una cosa; es lo que define la esencia de una cosa; es aquello por lo cual se distingue la esencia de una cosa; lo que dice el ser, único o múltiple, de una cosa. (Aristóteles, 2007: 10-11.)

8 Luis Villoro crítica al universalismo moderno por expresarse y mantener la forma de la homogenización. (Villoro, 1998: 27)

9 Emmanuel Lévinas hace una crítica a la filosofía moderna y en general a la filosofía occidental como pensamiento de la identidad. (Lévinas, 1987: 67.)

10 Deleuze y Guattari reflexionan sobre las fracturas de la unidad de la universalidad moderna que nunca volverá a darse ni siquiera en la unidad de las fisuras; aspecto que consideramos atraviesa tanto al pensamiento como a la política posmoderna. (Deleuze y Guattari, 1985: 47-48.)

11 Consideramos que la diferencia es una «forma» que define el ser de la Posmodernidad y que esto se ve reflejado en el tipo de política. (Pierpaolo Donati, “Lo postmoderno y la diferencia de lo universal", en Giner y Scartezzini (Coord.), 1996: 130) 
humano», sino también por las «formas del Ser». Aunque quizás la vía para comprender estas últimas sea comenzar por las primeras. Pensamos que dos «formas de valor» que nos pueden ayudar a acercarnos a las «directrices del Ser en alteridad» pueden ser el «contrapoder» (Villoro, 1997: 86-87), que retomamos de la ética-política de Villoro, porque es disruptivo y el «intervalo» ${ }^{12}$, que retomamos de la política de Jacques Rancière, porque permite vincular, pero en la diferencia, así como «unir desde/en la alteridad».

Consideramos que el «intervalo» de Rancière y el «pensamiento disruptivo», crítico, que se encarna a nivel político como «contrapoder» en las reflexiones de Villoro, ambos ubicados desde una política de la alteridad, permiten incorporar en las formas de la acción humana a las «directrices del Ser en alteridad»; es decir, las formas del valor, el intervalo y el contrapoder, nos ponen en franquía para dejarnos intervenir por el sentido del Ser en alteridad, en una comprensión que no es iniciativa de la subjetividad. Esto nos arrojaría, pensamos, una «política de la potencia del Ser».

Dicha política tendría como fundamento una racionalidad diferente a la «Moderna» ${ }^{13}$ y a la «posmoderna». ${ }^{14}$ Ésta sería una razón al servicio de la vida (Villoro, 2007: 205), sería una racionalidad ontológica, una racionalidad del logos del Ser en alteridad, que piensa esencialmente las formas del Ser en estado de alteridad y que implica una «descentralización radical»; en el pensamiento, una des-subjetivación y una «epojé profunda» ${ }^{15}$ e incluso una interrupción del pensamiento mismo; en la política, conllevaría una descentralización

12 Como desarrollaremos más adelante, Jacques Rancière ha hablado ya del «intervalo» en la política reflexionando sobre la idea de la comunidad política. (Rancière,1996: 170-171)

13 Un caso ejemplar es el pensamiento de Descartes con quien inicia el racionalismo moderno aspirando a un conocimiento universal desde un sujeto puro de conocimiento. Así lo destaca Francisco Larroyo en el estudio introductorio que hace de la obra de Descartes "Descartes fundador del racionalismo" (Larroyo, 1976: IX-XXIV).

14 Nos apegamos a la delimitación de filosofía posmoderna y a la crítica que expresa de ésta Mauricio Ferraris en el Manifiesto del nuevo realismo, (Ferraris, 2013:39-68).

15 Epojé en el sentido de lo que Marc Richir ha llamado "epojé fenomenológica hiperbólica". (Richir, 2012: 329-332). 
no solo del poder del Estado, sino de todo poder humano, virando más bien hacia (la potencia) del Ser (contingente), que es lo valioso por excelencia y excedencia, simplemente porque «es».

¿Pero, entonces, cómo pasamos de una política de lo óntico a una política ontológica?: ¿cuál es la mejor vía para la transformación política?

Pensamos, con el filósofo mexicano Luis Villoro, que el mejor camino para la transformación política es la vía ética y agregamos que esto es cierto, siempre y cuando se logre cambiar la forma de la política a nivel ontológico; es decir, toda vez que se logre cambiar su forma de ser. Para ello, consideramos que el pensamiento ético tiene que intersecarse con la dimensión ontológica en la que se vincula el «Ser-del-devenir» y no limitarse tan solo a la moralidad social humana (en la que intervienen relaciones de poder a nivel intersubjetivo); asimismo, debería dejarse orientar por una «razón razonable» (Villoro, 2007: 205-222) que incorpore, a su vez, los movimientos de las directrices del logos del Ser en alteridad.

Pero vayamos con calma, 1) ¿qué tipo de racionalidad es la adecuada para pensar las prácticas y procesos de la ética y de la política?; 2) ¿qué es la ética? y ¿cómo es su dimensión ontológica?; 3) ¿qué es la política? y ¿cómo es su estructura ontológica?; 4) ¿es posible cambiar la estructura ontológica de la política?

Para contestar estas preguntas, permítasenos delimitarnos a una reflexión sobre la política moderna porque consideramos tiene reverberaciones profundas todavía en la época actual, a pesar de haberse presentado ya su crisis en la Posmodernidad. Para ello recurriremos a la filosofía de Villoro, quien realizó profundos estudios sobre la ética (los valores morales) y sus vínculos con la política (el poder): construyó una teoría del valor para poder reinterpretar el pensamiento político, en particular, de la época moderna, a partir de clásicos tales como Maquiavelo, Rousseau y Marx para, así, comprender los problemas ético-políticos nuestra actualidad y de nuestro contexto social mexicano (Villoro, 1997). 
La racionalidad en el ámbito de la ética y de la política

Comencemos por la primera cuestión: ¿qué tipo de racionalidad es adecuada para pensar los procesos de la ética y política?

Luis Villoro muestra que, en el fondo, el problema de la política moderna fue el tipo de racionalidad con la que ésta operó y en la cual se articuló: la racionalidad instrumental. Las características de ésta fueron: ser esencialmente abstracta, usar la representación conceptual y una lógica de cálculo, ser estratégica y, especialmente, constituyó un medio para lograr ciertos fines, entre los cuales destacó el de la dominación; ${ }^{16}$ es decir, servir para justificar las acciones de una política falta de ética; crear formas conceptuales torcidas, respecto de la línea de la perfección a la que aspiraba, como es el caso de la ideología y la utopía, máquinas conceptuales que han contribuido a la alienante dominación del hombre por el hombre (Villoro, 1997: 175-221). Como alternativa ante dicha racionalidad y ante la desilusión de la misma, ocurrida en la Posmodernidad, Villoro propone la «racionalidad razonable» (Villoro, 2007: 205-222).

La «razón razonable» pone en juego también una «racionalidad valorativa» y busca el «justo medio» entre ésta y la racionalidad instrumental, desde la cual es posible dar un fundamento sólido a la ética y pensar en una política con ética (Villoro, 1997); pone peso del lado del valor y no sólo del lado del poder, diferenciándose de la racionalidad moderna; se fija en «lo otro» que la racionalidad instrumental. Pone su atención no en el ente y la representación, sino en el «sentido» y el «valor» que se articulan en la relación y no en la sustancia.

La razón razonable de Villoro es una razón concreta y circunstancial al servicio de la vida y, a diferencia de la racionalidad moderna, es: múltiple, incierta, impura, dialógica y se construye en los límites de la condición humana (Villoro, 1997: 68).

Por lo anterior pensamos, con Villoro, que en nuestra época es necesario seguir usando la razón, porque la razón es necesaria para

16 Idea que podemos ver a lo largo del libro (Villoro, 1997); y que vuelve a expresarse en (Villoro, 2007). 
la vida humana, pero no en el sentido del paradigma moderno, ni en el posmoderno, sino en el de un paradigma contemporáneo que implica la puesta en marcha precisamente de la racionalidad que nos ha dejado de legado Villoro: la «razón razonable», que abre paso, consideramos, a una «racionalidad de la alteridad» o racionalidad ontológica - porque coinciden en la dimensión del valor-que expresa el sentido del Ser bajo formas de la no-identidad y de la noambigüedad, bajo las formas del valor, y permiten crear «intervalos de valor en alteridad»; es decir, permiten vincular el valor del Ser con los acuerdos y desacuerdos de las relaciones intersubjetivas para contrarrestar el peso del poder humano dominante (que ha sido ejercido por parte de la política de lo óntico), buscando como alternativa la orientación de la potencia del ser contingente del devenir.

La racionalidad ontológica, o de la alteridad del Ser, nos permitiría no solo hacer una evaluación prudente y pertinente de los actos y acontecimientos políticos - que regularmente se han hecho desde un enfoque antropocéntrico, subjetivo e intersubjetivo-, sino que nos permitiría actuar bajo una nueva orientación ética articulada y surgida en el espacio y tiempo que se articula entre de las relaciones sociales y el Ser desde una perspectiva no-antropocéntrica; es decir: nos permitiría construir una política basada en la potencia del Ser, guiada por el valor de la potencia del Ser -visto desde una perspectiva de alteridad-, que oriente los acuerdos intersubjetivos (que generalmente han sido basados en el poder humano que ha sido signo de dominación): sería una política de «intervalos en alteridad», una política ontológica que reemplace o, por lo menos, que equilibre, a la política del ente, de la identidad y la representación.

La racionalidad o logos del Ser, que pensamos va por el camino que surca la racionalidad razonable de Villoro, solo que hace énfasis en que la razón no está sólo del lado de los seres humanos (del yo y del otro), sino también del lado del Ser, (no solo el otro humano, el prójimo, puede ofrecer significaciones razonables, sino el también lo otro que el humano: el Ser); además, tiene el antecedente de la «racionalidad hermenéutica», que presenta Mario Teodoro Ramírez, siguiendo también a Villoro y a otros filósofos como Gadamer y Ricoeur y que define como "la capacidad de comprender 
interpretativamente a lo otro -a lo Otro, lo sagrado, pero también a los otros, distantes y cercanos, y, en fin, a la otredad en general-" (Ramírez, 2011:181). Ello, con la diferencia de que la racionalidad que proponemos no trabaja una materia -ejemplo extremo: el caosy la convierte en sentido, en forma (Ramírez, 2011: 185), sino que deja que las «formas en alteridad» que dibuja el caos irrumpan en el pensamiento y muestren el sentido; deja que el caos y la contingencia del Ser «interrumpan» el discurrir de la racionalidad y las acciones humanas, las contempla y las comprende sin imponerle formas y sentido de la identidad ni de la ambigüedad. «Las comprende en alteridad», porque realiza una «époje radical» ${ }^{17}$ del pensamiento de la subjetividad, incluso de la subjetividad entendida como «corporeidad» (Merleau-Ponty, 1993: 85-312) e incluso, más que una epojé radical fenomenológica porque dicha interrupción no es iniciativa de la conciencia sino del Ser.

En suma, y respondiendo a la pregunta inicial de este apartado, Villoro sostiene que la racionalidad adecuada para pensar la ética y la política es la «racionalidad razonable». Nosotros ratificamos su aseveración y proponemos una «racionalidad ontológica» de las «significaciones en alteridad» para unir esfuerzos en ese sentido; además, pensamos que es prudente incluir a la «racionalidad hermenéutica» de Ramírez para comprender dichos procesos, así como otras complejidades de la existencia humana en general, porque propone una perspectiva de otredad. Los tres tipos de racionalidades estarían enfocadas a la construcción de un nuevo paradigma o de nueva «figura del mundo» (Villoro, 1995: 136-145) con un enfoque de alteridad que difiere a la perspectiva de homogenización en la identidad que se da en la Modernidad y de fragmentación en la diferencia de la Posmodernidad.

Desde la «racionalidad ontológica de la alteridad» nos peguntamos de manera general: ¿existe un vínculo específico entre el Ser y la moralidad social humana (intervenida por fuerzas de poder político)?, ¿es posible pensar el bien común en la orientación del Ser en

17 Como decíamos, epojé en el sentido de la "epojé hiperbólica" de Marc Richir. (Richir, 2012: 329-332) 
alteridad? y, particularmente ¿cómo podemos cambiar la estructura ontológica de la política a partir del pensamiento racional ético?

La anterior pregunta, prácticamente corresponde a la última del complejo de cuestiones de este ensayo. Pero, para reflexionar sobre ésta, es necesario primeramente saber, con mayor precisión, en qué consisten la ética y la política (correspondientes a la segunda y tercer pregunta), así como los pormenores de la vía ética para la transformación política (correspondientes a la cuarta de nuestras preguntas), a las que iremos agregando los elementos del «atajo ontológico».

Permítasenos irlo definiendo apegados a la filosofía de Villoro, de quien vamos a mostrar, de manera paralela, la hipótesis interpretativa de que, en su filosofía, el fundamento de la política es la ética, como que el fundamento de ésta es tanto epistemológico como ontológico. Con ello, creemos mostrar que ya hay en la filosofía de Villoro algunos elementos implícitos de una ontología de la política.

La ética: Su objeto de estudio y su dimensión

Podemos definir a la ética, en el marco de la filosofía de Villoro, como la disciplina de la filosofía estudiosa de la actitud humana - entendida como aquella disposición del comportamiento en la que se tiene la experiencia subjetiva del «valor», en la que se construye la noción del bien individual-, y de las relaciones intersubjetivas, en las que se experimenta y se define, racional y dialógicamente, el valor de forma objetiva, implicando la articulación de la noción del bien común (Villoro, 1995: 178). Siendo la actitud, específicamente, una disposición adquirida en la que se observa algo favorable respecto de un objeto o situación objetiva donde, precisamente, lo que provoca ese algo favorable es lo valioso, «el valor». El valor es el término de esa actitud favorable. El valor es lo deseable porque es lo otro que la carencia y tiende hacia lo más óptimo o, si se prefiere, hacia el Bien; ${ }^{18}$ es aquello que alivia las privaciones, aplaca las tentaciones

18 Consideramos que en la ética de Villoro en gran medida influye la ética de Aristóteles: la orientación del valor es la idea del bien (Aristóteles, 1942: 67). 
del deseo, cumple los anhelos, vuelve pleno a un mundo carente (Villoro, 1997: 16); es aquello que eleva la moralidad humana de una moralidad vulgar e irracional a una razonable y celeste. ${ }^{19}$

A la anterior definición, apegada a la filosofía de Villoro, agregamos el elemento ontológico: la ética estudia ${ }^{20}$ la moralidad humana, individual y social, en la que se da la disposición a actuar entre el bien y el mal, misma que se vive subjetiva e intersubjetivamente, y sus relaciones con el Ser, en las que se inter-forma la «dimensión del valor».

Así, ontológicamente, podemos decir, matizando algunos aspectos de la teoría de Villoro y siguiendo a Husserl, a quien conocía perfectamente Villoro (Villoro, 1975), que la dimensión del valor se articula entre el Ser y la pluralidad (Arendt, 1997: 45-46; Arendt, 2009: 21-22) de seres humanos, ${ }^{21}$ en la coordenada de la vitalidad del mundo vivido o mundo de la vida (Lebenswelt), ${ }^{22}$ donde fluyen y se engarzan las corrientes de vivencias de los seres humanos y los seres existentes del mundo, siendo éste su puente y sus articulación. Dicha dimensión se articula entre tres registros:

1) uno subjetivo, relativo a la «conciencia moral» del sujeto, que no se genera en el puro pensamiento ni en el puro sentimiento o afectividad, sino en el comportamiento, que implica ambos componentes, además de la acción y la articulación de creencias que se construyen teniendo algo como verdadero del mundo real; a partir de este proceso, el sujeto se dispone a actuar diferenciado racionalmente entre el bien (lo valioso) y el mal (lo no valioso);

19 Usamos la distinción que hace Platón entre lo vulgar y lo celeste de eros (Platón, 2009:521-522), para enfatizar la idea de Villoro en la que relaciona al valor con el deseo (eros) y éste a su vez con su forma terrestre y su forma celeste (Villoro, 1997:14-15)

20 Decimos lo siguiente agregando a la teoría de Villoro, pero continuando en la línea fenomenológica (husserliana).

21 Desde una mirada desde luego antropológica aunque no antropocéntrica, puesto que pretende desbordarse hasta la afirmación del valor de cualquiera y para todo ser viviente.

22 (Husserl, 1984: 174.) 
2) otro, intersubjetivo: referente al espacio en el que los diversos seres humanos comparten la experiencia del valor y encuentran «necesidades básicas» comunes entre ellos, ante los que pueden buscar bienes sociales;

3) y uno existencial: en el que se tiene la experiencia del valor «a ras del ser de la existencia», en los movimientos de la vida misma, vida que se comparte y que implica no sólo la experiencia del valor derivado de la conciencia moral de las subjetividades y de las relaciones intersubjetivas, sino de las relaciones con el ser-del-devenir.

La «dimensión del valor» tiene un suelo originario de «Ser», el ser puesto por el Ser mismo, que posibilita que las experiencias intersubjetivas sean en común, pero éste se articula también entreverado por las relaciones mismas de los seres humanos y seres vivientes del mundo existencial. La dimensión del valor, en la filosofía de Villoro, podemos interpretarla ontológicamente como la esfera limítrofe entre dos tierras, la del mundo vivido de los seres humanos y la del Ser, en la que acontece la experiencia del valor. Incluso podemos afirmar, en este respecto, que Villoro piensa a la ética, más de manera ontológica (del ser) -incluyendo también una postura contextual-histórica, como la de Hegel-, que de manera deontológica (del deber ser), a la manera kantiana, aunque se percata de la importancia de ambas posturas (Villoro, 1997: 223-248).

Ahora bien, la experiencia de la dimensión ontológica del valor, que ponemos de relieve en este ensayo, es posible evaluarla razonablemente a partir del criterio epistemológico que plantea Villoro, en el que es posible evaluar la experiencia del valor de forma objetiva pretendiendo alcanzar la universalidad del valor de otro modo distinto al moderno, a saber, a partir de la búsqueda de la objetividad del valor - desde los esquemas de la sabiduría (conocimiento personal) y no desde los de la ciencia (conocimiento objetivo)- que se logra con base en la exposición de las «razones suficientes para creer que algo es valioso», aunque no de razones objetivamente suficientes para creer; pero, aún así, «se pretende» llegar a considerar lo valioso de manera objetiva a partir de lo común entre la intersubjetividad y llegar a un momento en que se considere valioso con independencia 
de los sujetos que lo juzguen, por lo que dicho planteamiento lo consideramos realista y con fundamentos ontológicos implícitos (Villoro, 1982: 241-244)

Por lo anterior, vemos que la ética de Villoro tiene un fundamento epistemológico que está pensado desde una «racionalidad razonable», que da razones suficientes para creer en valores comunes, valores objetivos, desde el acuerdo racional intersubjetivo; pero que también tienen su arraigo en la realidad vivida, en el «ser en común», y, por ende, remiten a la experiencia de la realidad que cualquier sujeto puede experimentar y que, por lo mismo, puede ser compartida, mostrándose así, también un fundamento no sólo racional del valor, sino también ontológico. Vale decir que es en esa dimensión ontológica del valor es donde coinciden la razón razonable de Villoro y la racionalidad de las significaciones en alteridad que pensamos nosotros.

Ahora bien, ¿qué pasa con la ética desde el ámbito propio de la moralidad social y del poder?

¿Qué es la ética política?

Centralmente, la ética de Villoro estudia la moralidad social (Villoro, 1997: 175-197), no solo la moralidad individual, y se preocupa por el bien de todos los miembros de la polis, por el bien común. Por ello, su ética es una ética política. Su reflexión va encaminada a que los seres humanos eleven su moralidad del nivel en el que se encuentran a uno superior.

Sostiene Villoro: "la propuesta de una ética política parte de una moralidad existente, condicionada por relaciones sociales reales; la supone, pero no se reduce a ella; tiene que someterla a crítica, en base a razones. Está motivada por intereses de los sujetos pertenecientes a una colectividad, pero tiene que establecer los valores que correspondan al interés de todos" (Villoro, 1997: 236). La ética política de Villoro combina prudentemente el valor con el poder para 
realizar la «transmutación de los valores» ${ }^{23} \mathrm{y}$, así, pretende lograr una moralidad más elevada a través de valores comunes, compartibles y realizables, es decir, bajo el criterio de la objetividad del valor (una objetividad que se logra en el diálogo razonable intersubjetivo), pero 1) tomando en cuenta la experiencia particular de la vivencia del valor de cada persona (su experiencia ontológica del valor) y 2) sometiendo ésta a una criba razonable y epistemológica, ${ }^{24}$ para buscar «valores en común».

Enunciando las características de los valores en política, Villoro afirma que "una ética política trata especialmente de los valores que satisfarían el interés general de la asociación política; tradicionalmente responden al membrete de «bien común». Intenta determinar también su relación con los intereses particulares, de los individuos y grupos componentes de esa asociación" (Villoro, 1997: 73).

Desde ahí podemos ver que la tarea de una ética política es comprender el comportamiento moral de los seres humanos que viven en sociedad, que están sometidos a un sistema de poder a través de la diferenciación y discernimiento, pero a la vez de vinculación y complementación entre «el poder» (que opera con una racionalidad instrumental - podemos agregar: a nivel de lo óntico- y con un lenguaje explicativo y que pone su atención en los intereses particulares y de grupo), y «el valor» (que obra mediante una racionalidad valorativa -a nivel de lo ontológico- y utiliza un lenguaje justificativo y que busca el bien tanto para el individuo como para la comunidad).

La ética política de Villoro es disruptiva. Cuestiona el pensamiento reiterativo de la política que mantiene un sistema de dominación; procura la liberación política a través de un pensamiento

23 Nietzsche hablaba de la transmutación de los valores, Villoro de la transfiguración de los valores, ambos deseando una moralidad superior a la dada (moralidad de esclavos). (Nietzsche, 2009: 42) (Villoro, 1997:199-205; 2011: 7-11)

24 La pregunta es ¿qué tipo de conocimiento nos arroja la experiencia ética? La respuesta es que no nos da como resultado un conocimiento objetivo, sino sólo un conocimiento subjetivo que puede ser intersubjetivo y compartido, puesto que no constituye una creencia que pueda justificarse en razones objetivamente suficientes para creer, sino que a lo que más llega es a una ser una "creencia razonable" (Villoro, 1997:27) o "creencia compartida" (Villoro,1982: 241). 
ético. El objetivo del pensamiento ético, como actitud crítica moderada por una racionalidad razonable, es buscar la transformación o el paso de aquella política injusta, que regularmente usa a la ética solo para enmascarar y justificar su dominación, a una política justa que opere verdaderamente con ética haciendo «valer al valor», en la acción práctica, es decir, eficazmente, y esto no es posible con una ética sin más, sola, (puros valores), sino con una ética que use prudentemente los medios necesarios para lograr la realización de los valores; por lo tanto, se ocupa de un «un valor con poder».

La ética política de Villoro, tiene una máxima esencial que se expresa del siguiente modo: "obra de tal manera que tu acción esté orientada en cada caso por la realización en bienes sociales de valores objetivos" (Villoro, 1997: 246). El contenido de esta máxima puede desglosarse en cuatro principios de acción (Villoro, 1997: 246-247):

1) Una voluntad ética, en política, postula valores objetivos cuya realización constituiría un bien común, más allá de los bienes específicos de cada grupo .

2) Una voluntad ética, en política, está orientada por la sociedad proyectada.

3) Una voluntad ética, en política, quiere la realización de bienes sociales.

4) Una voluntad ética considera valores objetivos por realizar en cada caso.

Una de las virtudes de la ética del filósofo mexicano es traducir los valores vitales-ontológicos (que pudieran pensarse como abstractos e intangibles) a bienes sociales concretos, objetivos, comunitarios, así como, a principios formales y normas éticas. Sostiene Villoro, "una ética de la política puede expresarse indistintamente en una ética de valores o normas”(Villoro, 1997: 71-73). Pensamos que esto se debe a que los juicios que se realizan a la luz del valor pueden irse haciendo objetivos hasta lograr cierta consistencia tangible y llegar a traducirse en «bienes sociales concretos», gracias a la vía epistemológica razonable de su ética política. 
Vale decir que nosotros consideramos que estos trazos de la ética política de Villoro nos marcan la vía ética para la transformación política.

Ahora bien, ¿qué es la política?

La política: su ser social y su estructura ontológica

Interpretando a Villoro en lo referente al apartado tercero de El Poder y el valor (Villoro, 1997: 71), podemos observar que «la política» piensa los valores morales concernientes a la vida en sociedad sometida a un sistema de poder. Pero ¿qué es el poder? Quizás convenga definir a la política por su punto de apoyo.

Avanzando en este tema, Villoro señala primeramente que el «poder», en lenguaje ordinario es lo relativo a «fuerza», «capacidad», «dominio», «violencia» y que, dependiendo del contexto y en un sentido vago y general, puede decirse que es la capacidad de algo o alguien para causar efectos alterando la realidad (Villoro, 1997: 80); nuestro filósofo sostiene: "poder es dominio sobre sí mismo y sobre el mundo en torno, natural y social, para alcanzar lo deseado. Es el medio privilegiado para lograr un fin” (Villoro, 1997: 81). Ésto queda dicho en un sentido general. Pero afirma que el poder, ya en el ámbito de la política, nace del «conflicto social» y que en eso consiste precisamente la política: en la lucha por el poder en el interior de la sociedad (Villoro, 1997: 81).

En este sentido político, sostiene Villoro, el poder, "es el peor mal porque consiste en la ruptura del vínculo social y su remplazo por la violencia generalizada, que destruye la asociación misma y hace imposible la realización de cualquier bien común" (Villoro, 1997: 81-82) La política que opera con este tipo de poder es lo que nosotros hemos optado por señalar como una «política de lo óntico». En dicho escenario asevera Villoro que el poder político acontece cuando un individuo o un grupo de la sociedad imponen su voluntad sobre el resto de la sociedad para acabar con el conflicto. Pero podemos ver que el conflicto no termina ahí, sino que la lucha 
por el poder puede ser eterna. ${ }^{25}$ Señala Villoro que el poder político lanza, contra el mal de la violencia colectiva, la violencia de una parte sobre el todo. En eso consiste el «nacimiento del poder político». Podemos decir que ese es el nacimiento ontológico de «la tragedia de la política».

Afinando su definición sobre el poder político, afirma Villoro que se trata de un poder sobre los hombres, que no consiste tanto en la capacidad de realizar un fin querido como ocurre en la modificación de la realidad material. Ahí observamos que tiene mucha fuerza el poder político porque ejerce fuerza efectiva sobre la realidad, pero también ejerce fuerza efectiva sobre la voluntad de los seres humanos. En ese sentido, Villoro sostiene, el poder político es impositivo. Cuando la imposición se mantiene, se convierte en dominación: "El poder por sí mismo está obligado a restringir la libertad de quienes no lo ejercen. Su esencia es la dominación" (Villoro, 1997: 83). En este sentido, Villoro sostiene que, por esencia, el poder es lo opuesto al valor. En la distinción de la política que hemos hecho, la política de lo óntico correspondería al poder y la de lo ontológico, al valor.

Ya podemos observar que la política es, negativamente, el arte del uso del poder para el mantenimiento de la dominación de un todo de seres humanos por la violencia de una parte, a través de los medios necesarios para lograr dicho fin; es el conjunto de métodos, procedimientos y conocimientos con los que se rompe el vínculo social y se remplaza por la violencia generalizada, por lo que consideramos que la política también es la ciencia del mal.

Con este comportamiento, que es propio de la política de lo óntico, se pervierten todo tipo de relaciones humanas. Incluso, pensamos que puede corromperse a nivel de la asociación política originaria (fundamento ontológico de todo tipo de asociaciones entre seres humanos), al cerrar la actitud de acceso al «flujo del devenir intersubjetivo originario», con lo que se hace imposible la realización del bien común debido a los vínculos rotos, tanto de derecho como de hecho; pero esto es reversible, porque dicho flujo se mantiene en

25 Desde este escenario podemos colegir que en la historia de la humanidad ha demostrado que «lo único eterno en la Tierra puede ser la lucha por el poder». 
constante cambio y ésta es la base misma de la posibilidad de cambios de raíz en nuestra actividad y de los acontecimientos ontológico y políticos.

Por otro lado, positivamente, la política es el ordenamiento estructural, eficaz, de valores morales sociales que contienen la esencia del valor en nosotros. Sin embargo, regularmente el poder vigente los reduce a leyes positivas, cuya ejecución se logra con coacción y violencia; por ello, en lugar de realizar lo deseable (el valor) en la polis, por ejemplo, la justicia, comete injusticias que son signo de lo indeseable e inhumano en nosotros. Sin embargo, esta estructura corresponde a la política de lo óntico y de la representación.

Ahora bien, esa configuración de valores morales sociales que, pensamos, contienen incluso la esencia de «lo humano» en nosotros y que corresponden a las formas del valor tienen un fundamento ontológico en los «intervalos de realidad» que se articulan en las inter-relaciones entre el juego en las relaciones intersubjetivas y los misterios, la contingencia, el Ser (cuyo misterio más grande es que el Ser sea $)^{26}$ que se muestran en el «comportamiento humano», mismos que les dan a los seres humanos la posibilidad de organizarse en sociedad y crear principios y normas, es decir, organizarse en ciudades con reglamentos morales, cívicos, jurídicos, etc.

Esto lo decimos en el marco y en el horizonte de la filosofía de Villoro. Aunque él no haya desarrollado ideas relativas a una ontología de la política, podemos ver en algunos de sus textos, como El poder y el valor, que el ser de la política lo concibe articulado en la dimensión de la experiencia intersubjetiva humana, la dimensión del valor intervenida por las relaciones de fuerza del poder y relativo a la condición de la existencia humana. Para Villoro, la política es un asunto de la «condición humana» que se ha manifestado, a lo largo de la historia, mediante la dialéctica de un poder inauténtico (que es injusto y dominante) y un poder auténtico (justo y libertador).

26 Sigo a Villoro en el sentido de lo que subraya de san Agustín y de Wittgenstein respecto del milagro de que el mundo sea o de la experiencia de ver el mundo como un milagro (Villoro, 2006:122). 
Éste último, es un poder que hace resistencia al poder dominante, un «Contrapoder» (Villoro, 1997: 86-87).

El «contrapoder» sería la actitud y el modo con el que se procedería por una vía ética para la transformación política y, asimismo, con el que operaría una política con ética, una política razonable y, con ello, descubrimos que precisamente el «contrapoder» es una «forma del valor» que se orienta hacia el sentido del Ser en su alteridad.

Ahora sí, en vista de lo anterior, retomemos la pregunta por la transformación de la estructura ontológica de la política.

\section{La transformación de la política a nivel ontológico}

Pensando en desmantelar la artificialidad de la «política de lo óntico», que ha mostrado un modo de ser corrupto e injusto, vemos que su estructura es impermeable; no tiene porosidad. Es decir, no deja espacios para que el bien, la libertad y la justicia fluyan entre nosotros y, si ve que existen, los va cerrando. Por ello, consideramos que es necesario cambiarla: buscar cómo lograr «la porosidad» suficiente en su estructura de manera sostenida y, además, «construir nuevos tejidos de realidad política»; esto es, buscar el cambio en la estructura ontológica corrompida de la política a partir del pensamiento racional y de la ética. Asimismo, consideramos que este pensamiento ético-racional (disruptivo), puede lograr cambios en la estructura ontológica de la política, bajo la condición de anclarse a la contingencia del ser-en-devenir y, así, devenir un pensamiento ontológico, una racionalidad de las significaciones del Ser en alteridad; vinculándose no sólo al valor comprendido en los límites de la moralidad social humana, ámbito de la intersubjetividad, sino también al valor del ser-en-devenir incorporándose a su dinámica contingente.

Consideramos que la contingencia del ser-en-devenir (base del ser de las relaciones humanas desde la que se abre la posibilidad de la justicia, desde la libertad y la espontaneidad del Ser, del bien radical, porque cuando sucede, surge desde la potencia del Ser), se podría hacer valer por sobre las leyes de la necesidad de la política del ente, 
la identidad y la representación que degradan al «valor» reduciéndolo a «ley» jurídica, la cual ha servido para justificar la injusticia bajo «forma» del poder y basado en la lógica de la «racionalidad instrumental».

Entonces, ¿podemos perforar la estructura impermeable de la política injusta (política de lo óntico) y, a la vez, construir una espacialidad porosa, una nueva estructura ontológica de la política, que implica al conjunto de relaciones sociales humanas, con la porosidad suficiente, para que la justicia y el bien común acontezcan entre nosotros?

Primeramente es necesario mencionar resumidamente, como veníamos anunciando, que la filosofía de Villoro nos da a pensar, dos planos y modos del ser de la política:

1) el ser artificial de la política corrupta e injusta (política del ente) que ha sido construido de tal manera que es impermeable, su porosidad es cerrada y se articula según la lógica de la necesidad de la voluntad humana; y

2) el ser originario de la política (política del ser), en un plano abiertamente ontológico, que es fluyente y está articulado en la intersubjetividad que es la base de la sociabilidad, y que está fundada, a su vez, en el Ser en tanto que devenir y se articula según el orden de la contingencia del Ser.

Sin embargo, en los dos casos, el ser de la política o la realidad ontológica de la política no tiene esencia inmutable, sino que se construye entre los poderes de las relaciones intersubjetivas (que han sido históricamente inhumanas, malvadas e injustas) y del devenir existencial, y, por tanto, vemos que sí la podemos cambiar.

A partir del pensamiento ético-político de Villoro y de los apuntes ontológicos que hemos realizado en torno a un logos del Ser en alteridad y a una política ontológica de intervalos de valor del Ser en alteridad, vemos, dos maneras de transformar dicha estructura: una disruptiva y otra constructiva. La primera aplicaría para una política corrupta e injusta (política de lo óntico), que tiene que ser modificada a través de un pensamiento y acciones críticas contra el poder 
dominante e injusto, perforando su injusta realidad; la segunda, se pondría en marcha para la articulación de nuevas relaciones de "lo político", ${ }^{27}$ a través de uniones vinculadas en la liga de «intervalos de valor». ${ }^{28}$ El primer modo, moderado por un «criterio razonable» (Villoro, 1982: 197-221) fundamentado en una «racionalidad razonable» (Villoro, 2007: 205-226). El segundo modo, dinamizado por una racionalidad ontológica que mantiene su perspectiva en el horizonte de las formas del Ser en estado de alteridad.

Es decir, pensamos que la porosidad en la estructura de la política es posible realizarla de dos maneras:

1) por medio de la actitud disruptiva «el contrapoder» del pensamiento ético de la filosofía de Villoro, puesto que funcionaría como un taladro crítico que perforaría la estructura impermeable de la política para crear huecos, poros, orificios que permitieran que lo humano fluyera entre su espacialidad; y

2) por la articulación de las relaciones humanas en «intervalos de valor», desde una perspectiva de alteridad que crearía tejido político no necrosado, un tejido que incluye a la materialidad del sentido del Ser en alteridad.

Para Villoro, el «contrapoder» es un poder libertario que expresa la voluntad del pueblo; no es impositivo, sino expositivo del bien común; no es violento, usa una no violencia activa, como por ejemplo las huelgas, la disidencia crítica, individual o colectiva, la resistencia organizada de grupos de la sociedad civil frente al Estado, la desobediencia civil, etc; opone la resistencia de un valor comúnmente aceptado contra la imposición del poder dominante.

Villoro expone que, aunque suelen confundirse en el uso y los discursos, hay diferencias notables entre poder y contrapoder,

27 Hannah Arendt diferencia entre "lo político" y "la política" (Arendt, 1997: 83-84)

28 Lo más cercano a los intervalos de valor ontológicos que queremos destacar lo encontramos ya apuntalado por Jaques Rancière en la parte final de El desacuerdo. Política y filosofía cuando expone lo referente a los "intervalos políticos". (Rancière, 1996:171) 
advierte cuatro, pero falta de espacio permítasenos citar aquí únicamente los dos últimos del orden en que los menciona:

1) El poder impositivo, puesto que tiene que doblegar las voluntades ajenas, no puede menos de ser violento. [...] El contrapoder, en cambio, intenta detener la violencia del poder. Puesto que no im-pone sino ex-pone su voluntad ante los otros, su ámbito es el de la comunicación, no el de la violencia. Si pudiera ser totalmente puro sería no-violento. Contra la imposición del poder opone la resistencia de un valor comúnmente aceptado. Sus procedimientos son, por lo tanto, contrarios a la violencia. Ejercen una no-violencia activa. Sus usos son negativos: la huelga, la disidencia crítica, individual o colectiva, la resistencia organizada de grupos de la sociedad civil frente al Estado, la desobediencia civil, etc. Otras acciones son positivas; intentan reemplazar, en todos los espacios sociales, la imposición por la tolerancia, el conflicto por la cooperación, el enfrentamiento por la negociación y el diálogo. Así como el máximo poder lleva consigo la máxima violencia, el máximo contrapoder tiende a establecer la mínima violencia.

2) El fin del poder es lograr el mayor dominio del todo social por una de sus partes. El fin del contrapoder es alcanzar el dominio del todo social por sí mismo. En su límite plantearía la abolición de todo poder (Villoro, 1997: 86-87).

Por lo que concierne al «intervalo» es menester hacer a alusión al concepto que Rancière aporta al ámbito de la política, sin embargo, también es necesario expresar una observación. Para Rancière:

El inter del interesse político es el de una interrupción o un «intervalo» $[. .$.$] Los «intervalos políticos» se crean al separar una con-$ dición de sí misma, se crean al extraer rasgos entre identidades y lugares definidos en un sitio determinado de un mundo dado, identidades y lugares definidos en otros sitios e identidades y lugares que no tienen sitio en ellos. Una comunidad política no es 
la actualización de la esencia común de lo que no es dado como en común: entre lo visible y lo invisible, lo cercano y lo lejano, lo presente y lo ausente. Esta puesta en común supone la construcción de vínculos que unen lo dado a lo no dado, lo común a lo privado, lo propio a lo impropio. Es en esta construcción donde la común humanidad se incrementa, se manifiesta y surte efecto (Rancière, 1996: 170-171).

Para el filósofo francés, básicamente, los intervalos son el modo en que se articula la comunidad política, es la subjetivación política, pero dicha subjetivación no se da ni en el consenso racional, ni en la experiencia originaria de lo humano, sino en la «distorsión», en el «desacuerdo» mismo que es el modo de ser de la condición humana, que consiste en la ausencia de fundamento, en la pura contingencia del orden social (Rancière, 1996: 31). El intervalo se articula en la multiplicidad de fracturas que desunen la identidad de una comunidad consigo misma, para crear nuevas identidades en un lugar donde no existían, por ejemplo, el pueblo; es donde se da la inscripción de la parte de los sin parte (Rancière, 1996: 153). El intervalo se da en "la cuenta de los incontados" (Rancière, 1996:55).

Aquí es donde queremos señalar que el in-contado por excelencia en las relaciones políticas ha sido el ser-del-devenir, a éste, comúnmente, no se le da parte en los asuntos humanos. Rancière mantiene el tema de la política en el registro de la intersubjetividad, nosotros consideramos que hay que ensancharlo y desbordarlo hasta «la existencia del ser del devenir». Además, consideramos que es necesario pensar al intervalo no sólo desde una perspectiva de «identidad», originado en la fragmentariedad y diferencia, como una identidad gloriosa que se articula de forma disruptiva, sino pensarlo desde una perspectiva de alteridad, como la unión o vínculo entre las formaciones de las identidades humanas (con formas del valor), cualesquiera que estas sean, y el Ser en alteridad.

Estas dos maneras de lograr la porosidad en la estructura de la política pueden ir entrelazadas. Inclusive, la figura conceptual paradójica que proponemos, fundamentalmente, para la transformación de la política, es decir, para la perforación de la impermeabilidad de 
la política corrupta, es la de perforar con intervalos de valor desde una perspectiva de alteridad en sinergia con el pensamiento disruptivo y desde la contingencia de las acciones humanas y el acontecimiento histórico.

\section{Conclusiones}

Hemos llegado a la conclusión de que para hacer que el bien común acontezca entre nosotros no basta con pensar el «bien» $\mathrm{y}$ «lo común» en las relaciones entre nosotros, sino en las relaciones con lo que está más allá de nosotros - pero que a la vez nos articula desde adentro-: el ser-de-la-existencia. Hace falta pensar nuestra vida compartida (la moral social e individual) en el sentido del poder del Ser, que, consideramos, es lo valioso para orientarnos en nuestra existencia por la simple razón de que «es»y, así, no seguir orientándonos por el «poder humano» que ha construido a lo largo de la historia una trama de dominación e injusticia.

Pensamos que quizás, orientándonos por las directrices del sentido del Ser en alteridad, que no son construcciones del pensamiento humano y que, sin embargo, no se contraponen a los «intervalos de valor», podríamos lograr una descentralización del poder humano para componer una historia diferente de la humanidad: justa y libertaria. Observamos que para que haya una política con ética, tiene que haber no solo una ética política como propuso Villoro, sino que es necesario también que la ética política sea ontológica para poder pasar de una política injusta a una política justa.

Con Villoro hemos visto que la mejor vía para la transformación política es poner en marcha un pensamiento ético «disruptivo» que está delimitado por el horizonte del valor. Además, hemos observado que éste tiene que pensar no sólo la dimensión moral social humana, sino también la dimensión ontológica del valor (el valor en el sentido del Ser), para que así pueda realizar transformaciones de la política a nivel ontológico. Además, vimos que para lograr la porosidad suficiente en la estructura de la política de lo óntico (política injusta, artificial y alienante), es pertinente poner en operación 
permanentemente un pensamiento disruptivo, pero también construir nuevo tejido humano con relaciones humanas valiosas articuladas en el espacio común, no sólo público, sino existencial, entre las relaciones humanas y los movimientos del Ser del devenir.

A partir de Villoro hemos pensado que para que el ser humano no siga viviendo una política injusta y corrupta (política de lo óntico), sería deseable que no siguiéramos conduciendo nuestro comportamiento bajo las formas del poder (la ley, la homogeneidad, identidad, fragmentariedad, diferencia), sino bajo las formas del valor, de las cuales retomamos la del «contrapoder» de Villoro y la de «intervalo» de Rancière y proponemos: «los intervalos de valor» orientados por las «formas del Ser en alteridad», que permiten la unión prudente de los seres humanos a nivel ontológico. Con ello, nos referimos a las relaciones humanas articuladas en la libertad y la espontaneidad del acontecimiento ontológico de la política, en el que los movimientos del devenir del Ser intervienen en las relaciones intersubjetivas articulando acciones políticas con valor, justas, (no sólo en sentido antropológico sino des-antropologizado), mismas que se realizan impulsadas por la inercia del movimiento de la sinergia de dichas relaciones, lo que permite una «descentralización radical del poder», puesto que no es sólo una descentralización, por ejemplo, del poder del Estado, sino de cualquier poder humano, virando en lugar de esto a la potencia del Ser, de la que tenemos experiencia en la «dimensión de la realidad del valor», misma que se articula en las relaciones humanas en la espontaneidad y libertad del estar-aquí-reunido, porque en ella la potencia del Ser es lo valioso para el ser humano.

Según lo dicho, la política ontológica, que proponemos, sería aquella que dé muestras de cordura en un mundo político que ha perdido el juicio, realizando al fin un «intervalo lúcido en la política»; pero también, sería una política que puede crear un mundo de/ en/con valor ahí en el espacio y tiempo ontológicos que hay entre una persona y otra, aspecto que permite, observamos: «respeto en la proximidad» $\mathrm{y}$ «admiración en la distancia», valores deseables para una política humana de verdad. 
Finalmente, como alternativa a la mal-formación de política de lo óntico de la Modernidad y la política del simulacro de la Posmodernidad (que operan con formas del poder y que mantienen relaciones humanas injustas), proponemos una política ontológica opera con formas del valor, el contrapoder y los intervalos políticos, pero orientados por las formas del Ser estado de alteridad.

\section{Referencias bibliográficas}

Arendt, H. (1997). ¿Qué es la política? Barcelona: Paidós.

Arendt, H. (2009). La condición humana. Buenos Aires: Paidós.

Arendt, H. (2003). Conferencias sobre la filosofía política de Kant. Barcelona: Paidós.

Aristóteles. (1942). Moral a Nicomaco. Argentina: Espasa Calpe.

Aristóteles. (2007). Metafísica. México: Porrúa.

Deleuze, G.; F. Guattari. (1985), El Anti Edipo. Capitalismo y esquizofrenia. Barcelona: Paidós.

Donati, P. (1996). "Lo postmoderno y la diferencia de lo universal”, en Giner y Scartezzini (Coord.), Universalidad y diferencia. Madrid: Alianza, pp. 125-135.

Ferraris, M. (2013). Manifiesto del nuevo realismo. Barcelona: Biblioteca Nueva.

Husserl, E. (1984). Crisis de las ciencias europeas y la fenomenología trascendental. México: Folios Ediciones.

Kant, I. (2007). Crítica del juicio. Madrid: Tecnos.

Larroyo, F. (1976). “Estudio introductivo. Descartes, fundador del racionalismo, en Descartes. Discurso del método; Meditaciones Metafísicas; Reglas para la dirección del espíritu, Principios de la filosofía. México: Porrúa, pp. IX-XX.

Lévinas, E. (1987). Totalidad e infinito. Ensayo sobre la exterioridad. Salamanca: Sígueme.

Marx, C. (1979). Manifiesto del Partido Comunista. URSS: Editorial Progreso.

Merleau-Ponty, M. (1993). Fenomenología de la percepción. Barcelona: Planeta Agostini.

Nietzsche, F. (2009). El anticristo. Madrid: Alianza.

Platón. (2009). Diálogos. México: Porrúa.

Ramírez, M.T. (2011). Humanismo para una nueva época. Nuevos ensayos sobre el pensamiento de Luis Villoro. México: Siglo XXI/Universidad Michoacana de San Nicolás de Hidalgo. 
Rancière, J. (1996). El desacuerdo. Política y filosofía. Buenos Aires: Ediciones Nueva Visión.

Richir, M. (2012). “El sentido de la fenomenología”. En Investigaciones Fenomenológicas, 9 , pp. 315-332.

Villoro, L. (1962). Páginas filosóficas. México: Universidad Veracruzana.

Villoro, L. (1975). Estudios sobre Husserl, México: Universidad Nacional Autónoma de México.

Villoro, L. (1982). Creer, saber, conocer. México: Siglo XXI.

Villoro, L. (1995). En México entre libros. Pensadores del siglo XX. México: El Colegio Nacional/ Fondo de Cultura Económica.

Villoro, L. (1997). El poder y el valor. Fundamentos de una ética política. México: Fondo de Cultura Económica.

Villoro, L. (1998). Estado plural, pluralidad de culturas. México: Paidós.

Villoro, L. (2006). Vislumbres de lo otro. Ensayos de filosofía de la religión. México: Verdehalago.

Villoro, L. (2007). Los retos de la sociedad por venir. México: Fondo de Cultura Económica.

Villoro, L. (2011). “La realidad transfigurada”. En Devenires 23, pp. 7-11. 